Serviço de Clinica Cirurgica do Prof. Alipio Corrêa Netto

\title{
Um caso de peritonite encystada por ulcera duodenal perfurada (1)
}

\section{Cyro de Lauro Junior Quintoannista}

Vou apresentar aos collegas a observaçãa de um doente da 3. ${ }^{a}$ C. H., caso esse que acompanhei graças á orientação expontánea e generosa do nosso grande mestre e amigo dr. Eduardo Etzel.

O interesse da caso reside não na affecção em si mas principalmente nas circumstancias caprichosas que o rodearam e que acarretaram a impossibilidade da applicação de um tratamento cirurgico de urgencia, tratamento esse que o caso requeria.

Apresentou-se-nos a exame um doente sem febre portador, no baixo ventre, de um tumor volumoso, arredondado, duro, liso, doloroso.

Quinze dias antes, por occasião da ecclosão da sua molestia, o paciente chama um medico; este não chega a firmar um diagnostico mas não titubeia em receitar um opiacea, lançando deste modo o seu-doente aos azares da sorte ou, melhor dizendo, aos braços da morte.

Depois, as caracteristicas physicas do tumor levaram-nos ás mais variadas hypotheses.

E só então, depois de uma anamnese cuidadosa, brilhou a restea de luz que veio esclarecer o caso e dictar as providencias que a mesmo exigia.

(1) Trabalho apresentado no Departamento Scientifico em 16-3-37. 
A. D., branco, brasileiro, 36 annos, casado, pintor, residente na Capital.

QUEIXA - Quinze dias antes de sua entrada na Santa Casa sentiu uma dôr violenta no lado esquerdo apparecendo immediatamente no epigastro uma bolla dura do tamanho de um avo. No mesmo dia a bolla desappareceu sendo substituida por inchaço e endurecimento de todo o ventre.

HISTORI 1 PREGRESSA DA MOLESTIA ACTUAL Ha 5 annos be'seu cerveja, vinho e canninha; sentiu dôres fortes no epigastio e vomitou abundantemente. Durante varios dias vomitau todas as vezes que ingeriu alimentos. As dôres reappareciam após as refeições e se localisavam no epigastro e região umbellical; a sua intensidade augmentava progressivamente obrigando o paciente a ingerir chás caseiros com que melhorava. Desde então as dôres nunca mais o abandonaram: appareciam 3 a 4 horas depois do almoço, passando depois de algumas horas, ou permanecendo até o jantar e se prolongando, frequentemente, até de madrugada. Sentia azias frequentes e tinha regurgitações acidas. Fazia úso constante do bicarbonato. Vomitava com frequencia e os vamitos produziam acalmia. Muitas vezes accordou durante a noite sentindo azia; outras vezes levantou pela manhã com dôres discretas. Reparou que as refeições copiosas exacerbavam as seus padecinıentos os quaes não eram influenciados pela especie do alimento, excepção feita ao alcool, de que foi obrigada a absterse apezar de ser contumaz ethylista exagerado. Muita vez, quando os seus padecimentos attingiam ao paroxysmo, mitigava-os provocando o vomito introduzindo um dedo na garganta ou fazendo pressão forte sobre o epigastro. Tinha peridos de acalmia, de vinte dias a um mez, durante os quaes passava perfeitamente.

Seu dia gastrico era' o seguinte: tomava café simples com pão ás 7 horas; raramente appareciam a dôr e a azia que passavam lago ou se prolongavam com moderada intensidade até o almoço. Almoçava ás 11 horas: quando já tinha dôr e azia, estas se attenuavam para reapparecerem, exarcebadas, algumas horas depois. Quando não, appareciam 3 a 4 horas depois, persistindo geralmente até o jantar. Jantava ás 18 horas, hora que aguardava com impaciencia afim de poder largar o seu serviço de pintor e jantar para acalmar a azia que queimava o estomago. As dôres reappareciam de noite, prolongando-se, as vezes, até de madrugada quanda desappareciam.

Um anno depois consultou um medico que diagnosticou doença do figado"(sic) e receitou elixir paregorico com que o 
doente melhorou relativamente. De então para cá teve alternativas de melhoras e de aggravação. Como as suas dôres se exacerbassem, agora, de maneira insolita, durante a noite, deixou muitas vezes de jantar; caso contrario, as dôres o accordavam durante a noite sujeitando-a a vigilias innervantes.

Quando não tinha vomitos expontaneos, provocava-os como meio palliativo. Reparou, entretanto, que ultimamente os vomitos expontaneos eram menos frequentes porem mais abundantes: eram amarellados e continham grande quantidade de muco e restos alimentares que o paciente reconhecia como pertencendo a alimentos ingeridos até 3 dias antes. $O$ apetite estava diminuindo e arrotava constantemente com cheiro de ovos podres. Era portador de prisão de ventre habitual ficando no maximo 3 dias sem evacuar. Néga ictericia. Durante o tempo da sua molestia sentiu-se enfraquecer cada vez mais tendo emmagrecido 20 kilos.

No principio do anno passado consultou novamente a mesmo medico o qual reaffirmou o diagnoštico de doença do figado receitando novamente elixir paregorico e pillulas laxativas. Com isto melhorau relativamente até que, ha 15 dias atraz, pela manhã, ainda deitado, sentiu repentinamente uma pontada violenta no epigastro, apparecendo na região uma bolla dura cheia de cordõesinhos (sic) do tamanha de um ovo. Comprimiu institivamente $o$ tumor com ambas as mãos e sentiu que a dôr se irradiou para todo o abdomen e que o ventre ficou endurecida e meteorico. Desmaiou logo em seguida, cobrindo-se o corpo de suores frios, razãa pela qual a familia assustada chamou um facultativo da visinhança o qual disse não poder examinar o abdomen por este estar muito duro e que receitou gĉttas calmantes para tomar de 2 em 2 horas e uma formula em pó para tomar 10 minutos antes e 10 minutos depois das refeiçôes. Ao tomar a primeira dóse de gôttas vomitou pequená quantidade de liquido contendo borra de café (sic). No mesmo dia o tumor do epigastro desappareceu sendo substituido por um endurecimento de todo o ventre. Teve febre muito alta, que não mediu, e que permaneceu no mesma nivel nos dias subsequentes. Os vomitos de borra de café se repetiram durante 6 dias, diversas vezes ao dia. Durante esse tempo, para alimentar-se ingeriu apenas algumas colheradas de caldo. Ficou sem evacuar até o $6^{\circ}$ dia fazendo então um clister e tomando um purgante que ficaram retidos. No $8^{\circ}$ dia evacuou expontaneamente grande quantidade de fezes duras e pretas. Nunca ficou sem urinar, urinando sempre pouco de cada vez. 
Como os seus males não desapparecem, resolveu procurar a Santa Casa dando entrada na enfermaria 15 dias depois da ecclosão da sua molestia. Apresentava-se, então, com um tumor volumoso, arrendodado, duro, doloroso, occupando todo o baixo ventre. Tinha dôres discretas que se irradiavam para o dorso e para os testiculos. Não tinha febre.

Como antecedentes pessoaes conta que sempre gozou de bôa saude até 5 annos atraz e que até o inicio da sua molestia foi ethylista inveterado. Néga molestias da infancia e antecedentes venereo-syphiliticos.

\section{EXAME DO ABDOMEN}

Inspecção - Abdomen asymetrico, tenso, apresentando na parte baixa um grande abahulamento devido á presença de um tumor do tamanho de uma cabeça de creança, occupando todo o hypogastro, região umbellical até a cicatriz e parte das fossas illiacas internas. Á inspecção o tumor mostra-se arredondado, liso, de contornos bem delineados. $\mathrm{Ha}$ desapparecimento da respiração abdominal.

Papação - A palpação mostra um tumor volumoso, arredondado, liso, duro, dando ao tacto a sensação de uma bolsa cheia de liquido em grande tensão. O tumor é fixo, doloraso á palpação; a sua forma não se modifica pelas mudanças de posição. O abdomen é doloroso á palpação em toda a șua extensão. Não se palpa elemento algum da cavidade.

Percussão - A percussão demonstra uma area de massicez hydrica, em forma de circulo, abrangendo todo o hypogastro, região umbellical até a cicatriz, e fossas illiacas internas. Não se percutem alças intestinaes sobre ella. Signal do piparóte presente. As mudanças de decubito não modificam a area de massicez.

\section{TO'QUE RECTAL}

Pelo tóque verificou-se a obstrucção quasi total da ampolla rectal por um tumor fazendo saliencia $\mathrm{n}$ asua parede anterior. O tumor era doloroso á palpação e dava a impressão nitida de ser extra-rectal porque a mucosa era perceptivel ao tacta integra em toda a extensão.

A prostata era molle, de volume normal, não dolorosa.

Outros symptomas e signaes de algum interesse para a caso eram: posição indifferente no leito; excitação nervosa intensa e insomnia rebelde; respiração rapida e superficial; ausencia de phenomeno de Litten; pulso filiforme batenda 108 vezes por minuto. 
A historia do doente e o seu exame 'physico levaram-nos ao diagnostico de peritanite localisada por ulcera duodenal perfurada.

Necessario se fazia, entretanto, a confirmação deste diagnostico.

Tratar-se-hia, mesmo, de uma peritonite localisada?

Logo de inicio um facto importante chamou a nossa attenção: era o da localisação do tumor. $O$ tumor era mediano e enchia symetricamente todo o baixa ventre; a sua fórma era a de uma bolsa de contornos bem delineados contendo liquido sob tensão; dava, desse modo, a impressão nitida de uma bexiga distendida e cheia de urina.

Resolvemos, em vista disso, praticar o catheterismo da bexiga; introduzimos pela urethra, com relativa facilidade, uma sonda molle; houve sahida de $40 \mathrm{cc}$. de urina amarellada e limpida. Depois disso injectamos pela sonda, com seringa de vidro, 50 cc. de uma solução de permanganato de potassio; pouca depois aspiramos havendo a retirada dos mesmos $50 \mathrm{cc}$. Alem disso, não houve reducção do permanganato. da bexiga.

Pareceu-nos, então, de utilidade, praticar uma radioscopia

Debaixo do controle do écran radiologico, fái injectada, por sonda urethral, para contraste, uma solução de iodeto de potassio a $20 \%$. A bexiga encheu-se facilmente e a sua imagem se projectou apresentando, no polo superior, uma deformação em meia lua. Isto indicou uma compressão por um tumor externo ás paredes da bexiga.

Todos 'estes factos, alliados á posição habitual e estado normal da prostata, bem como a ausencia de antecedentes urinarios, comprovaram a não participaçãa da bexiga.

Como o tóque rectal tivesse mostrado o compromettimento do recto, achamas conveniente pesquizar o possivel gráu de compromettimento de outras porçôes do intestino grosso. Fizemos, para isso, uma radioscopia. Injectamos um clyster de baryo e levamos o doente ao écran: não obtivemos imagem. Collocando o doente em decubito dorsal, depois em decubito ventral, todas as manobras destinadas a fazer transitar o enteroclysma foram insufficientes para dar uma imagem do intestino. A passagem do baryo era impedida por uma obstrucção por compressão situada ao nivel da alça sygmoide.

Isto levou-nos a concluir pela existencia de um grande tunor extra-rectal. 
Assim, pois, o tóque rectal primeiro, depois a radioscopia to intestino, demonstraram que o recto e porção do collon estavam rebatidos pelo tumor a ponto de impedir a passagem do clyster de baryo.

Em vista disso, impunha-se uma radiographia da bexiga e do recto afim de verificar as relações destes argãos com'o tumor.

A radiographia foi praticada pelo dr. Paulo Toledo que nos forneceu o seguinte relatorio:

"Grande formaçãa tumoral do hypogastro, de contornos arrendodados visiveis directamente, comprimindo a bexiga em arco para baixo e o collon sygmoide para traz e desviando as alças delgadas".

"Não existem signaes de compromettimenta da bexiga, dos collons e do esqueleto da região".

Depoị disto não nos restava senão punccionar o tumor, o que foi feito na sala de operações estando o doente apto a ser operada si necessario.

A puncção foi feita na linha mediana, a $7 \mathrm{cms}$. acima da symphise publica, havendo retirada de uma amostra de um liquido puriforme de cheiro fétido.

Este facto commandou a intervenção immediata.

Com anesthesia local foi praticada a abertura da parede abdominal e do peritonio havendo sahida de quasi 2 litros de um liquido fétido, no inicio pouco turvo e depois francamente purulento. Em seguida collocou-se um dreno e fechou-se a cavidade. tonial.

Tratava-se, por conseguinte, mesmo, de um abcesso peri-

Restàva-nos agora diagnosticar a affecção que havia produzido a peritonite.

A dôr inicial, repentina, aguda, intensa, localisada; a defeza muscular localisada; o meteorismo; a febre subita; a estado syncopal, fallavam com eloquencia em favor de uma perfuração intestinal. Alem disto, corroborava esta hypothese a fetidez do puz escoado apoz abertura do abcesso.

Ora: a historia do doente, com um passado de ulcera do duodeno, e agora o quadro clinico, symptomatico, typico, da perfuração intestinal, levaram-nos a firmar o diagnostico de ulcera duodenal perfurada.

Entretanto, poderia tratar-se de uma perfuração localisada em outro segmento do tracto intestinal e que reconhecesse uma outra origem; por exemplo, perfuraçãa por febre typhoide. 
De facto, existe uma fórma clinica de febre typhoide que é uma fórma attenuada: é o "typhus levissimus" ou typho ambulatorio. Nesta fórma não existe o estado typhico: não ha febre e não ha symptomas intestinaes. Apenas mal estar, cephaléa, insonias abatimento. Mas ésta forma ambulatoria, desconhecida do doente e mesma do medico em virtude da sua benignidade, póde revelar-se subitamente manifestando-se pelo iliadro dramatico da perfuração do intestino.

No nosso caso, o passada gastrico do paciente não nos permettia a acceitação da hypothese de uma perfuração typhica; entretanto, o pronunciado estado de depauperamento do doente e odesejo de melhor esclarecer o caso, levou-nos a pedir uma Reação de Widal que foi negativa para T.A.B.

Cogitamos então do appendice, dada a grande frequencia da appendicite e das suas complicações peritoniaes.

As perfurações do appendice dão, geralmente, peritonites encystadas. Si o appendice é interno o abcesso peritonial póde ser mediano e o puz se collectar no hypogastro, por tabicamento das alças intestinaes, formando-se as vezes bolsas que chegam a occupar até mais de $1 / 3$ da cavidade abdominal.

Quando o appendice se perfura apparece tambem o quadro symptomatico do abdomen agudo: alteração do pulso e da respiração, paralysia intestinal, meteorismo, vomitos, facies abdominal.

Mas o interrogatorio do doente, nas perfuraçóes, revela sempre, antes da formação do fóco purulento, a dôr e a defeza muscular localisadas ao nivel da viscera affectada. Assim, si fosse peritonite appendicular, o doente revelaria, de inicio, dôr e defeza muscular no quadrante inferior direito do abdomen. Além de que, na peritonite appendicular, a dôr cresce gradualmente, e mesmo quando se extende a todo o abdomen é sempre - quadrante inferior direito que é a região mais sensivel. biliares.

Poderia tratar-se de uma peritonite por ruptura das vias

Poderia ser uma cholecystite, suppurada ou não, que se tivesse aberto no peritonio. A cholecystite manifesta-se quasi sempre por pequenas crises paroxysticas - crises de 3 dias com intervallos de bôa saúde de mezes.

O quadro symptomatico da cholecystite não tem o caracter nitido dos periodos da ulcera do duodeno. Ambas as affecções apresentam dôres de evolução nitidamente periodica no decurso do anno. $\mathrm{Na}$ ulcera do duodeno os doentes soffrem por periodos de 3 semanas aproximadamente, com sedações longas e perfeitas. 
Para Gutmann, este é o mais importante, o mais constante e o mais evidente caracteristico da ulcera, do duodeno. Nas cholecystites, calculosas ou não, os doentes soffrem por periodos curtos de 3 dias separados por intervallos de semanas ou mezes.

Si fizermos uma representação eschematica das crises vesiculares e crises da ulcera, teremos:

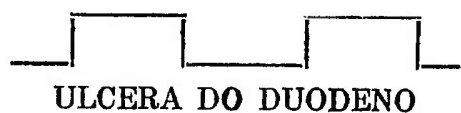

Quer dizer, a vesicula apresenta o quadro da dyspepsia reflexa, caracterisada par crises pequenas de 3 dias, de menor amplitude e separadas por intervallos de varios mezes; ao passo que a ulcera do duodeno apresenta o quadro da dyspepsia organica, caracterisada por crises de maior amplitude e maior duração separadas por intervallos de 15 dias a $1 \mathrm{mez}$.

Outro caracter de certa importancia reside no papel desempenhado pelos vomitos; na ulcera do duodeno, quando a dôr attinge o acmé, si sobrevem o vomito, a acalmia é rapida; na cholecystite o vomito não tem influencia alguma sobre a intensidade da dôr: o vomito não minóra, não acalmá.

Além disso; geralmente, a dôr da cholecystite apparece bruscamente, não é post-prandial, não tem habitualmente relação com a alimentação, nem hora fixa e é dôr constante que nâo se modifica pela ingestão de bicarbonato ou de alimento. $\mathrm{O}$ appetite fica diminuido e ha estado nauseoso em jejum. A dôr termina tambem bruscamente.

As vezes, entretanto, a cholecystite apresenta uma symptomatologia gastrica simulando a ulcera do duodeno. Porém as crises são sempre de 3 dias com intervallos de varios mezes de bóa saude. São, alem disso, sensibillissimas ás mudanças de regimen alimentar, sendo despertadas, geralmente, por algum alimento que o doente sabe qual é - gordura, ovas, chocolate, carne de porco.

Finalmente, poderia tratar-se de uma peritonite consequente a uma occlusão intestinal.

$O$ intestino estrangula-se mettendo-se num annel, passando por baixo de uma brida fibrosa tensa ou prendendo-se num diverticulo de Meckel: é o estrangulamento interno ou occlusão intestinal, que pode produzir a ulceração por necrose.

A constricção aguda do intestino produz dôr violenta, ineteorismo, retensão completa de fézes e gazes e signaes de 
septicemia peritonial. Os vomitos são incoerciveis e fecaloides. A dôr é continua com exacerbaçóes provocadas pelas contracções peristalticas.

Havendo perfuração da alça accentuam-se os signaes de septicemia peritonial.

O nosso doente teve vomitos de borra de café - que são hematemeses - mas não teve vomitos fecaloides e as suas dôres não apresentavam exarcebações.

Assim, pois, excluidas éstas diversas hypotheses, subsistiu c primeiro conceito de perfuração do duodeno.

O doente foi, então, novamente levado para a meza de operações sendo operado pelo prof. Alipio cuja intensão era a de suturar a ulcera. $O$ professor praticou a laparatomia mediana supra umbellical e uma vez aberto o peritoneo verificou a presença de numerosas adherencias entre a face anterior e inferior do figado, face anterior do estomago, e o peritonio parietal anterior; desfeita em parte éstas adherencias, nada conseguiu verificar nas paredes anterior e posterior do estomago. Em seguida procedeu á exploração do duodeno, com extremo cuidada agora afim de evitar a ruptura das adherencias; por esse motivo não conseguiu verificar a presença de ulcera perfurada; deu, então, por finda a exploração e fechou a cavidade. Em segui-

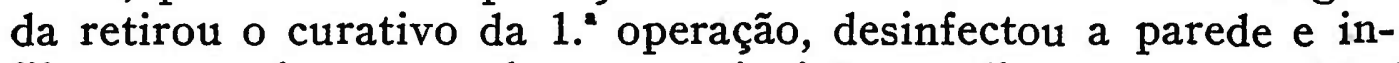
filtrou os planos; prolongou a incisão mediana supra pubica e procedeu a uma exploração rapida da cavidade; como esta tivesse resultado improficuo para o esclarecimento do caso,drenou a cavidade e fechou a parede abdominal.

Convem accentuar que durante toda a permanencia do doente na enfermaria foi instituido um rigoroso e intenso tratamento geral tendente a sustentar as suas forças e melhorar as suas condicções de resistencia que eram assaz precarias.

Dois dias depois o doente veio a fallecer e o seu cadaver foi enviado ao laboratorio de Anatonia Pathologica da nossa Faculdade, tendo sido necropsiado pelo dr. Amorim cujo laudo foi o seguinte:

"Molestia principal:

Ulcera duodenal perfurada".

"Encontrava-se no duodeno uma ulcera peptica, do tamanho de $\mu$ ma moeda de 100 rs., de bordos escalonados, perfurada sobre a face inferior do figada Um trajecto obliquo para traz 
e para a esquerda encontrava-se sahindo da ulcera e dirigindose para um abcesso situado na face inferior do diaphragma".

"No fundo do sacco vesico-rectal havia outro grande abcesso ccritendo puz de aspecto leitoso".

Evidentemente, o nosso doente foi portador de uma peritonite encystada por ulcera duodenal perfurada. 